\title{
The Value of China's Legislation on Plastic Pollution Prevention in 2020
}

\author{
Jianli Liu' ${ }^{1}$ - Yunfei Yang ${ }^{2} \cdot$ Lihui An $^{3} \cdot$ Qiang Liu $^{4} \cdot$ Jiannan Ding $^{5}$ \\ Received: 6 April 2021 / Accepted: 23 August 2021 / Published online: 4 September 2021 \\ (c) The Author(s), under exclusive licence to Springer Science+Business Media, LLC, part of Springer Nature 2021
}

\begin{abstract}
It has taken 12 years since 2008, but China is finally strengthening plastic pollution prevention and control through legislation. In an effort to regulate and control plastic products, China's government amended and released a series of laws and regulations in 2020, possibly heralding the end of China's plastic pollution. China's plastic pollution legislation, while late, is a viable and right response to the severe environmental and ecology problem. Legislative progress in plastic pollution prevention has extended beyond China government's administrative capability but has also been an important step in the protection of the environment in the world.
\end{abstract}

Keywords Plastic pollution $\cdot$ Law and legislation $\cdot$ Legislative progress $\cdot$ Plastic limit order $\cdot$ Plastic products $\cdot$ Disposable plastics

Attempts to craft laws aimed specifically at reduction and prohibition for environmental protection of the production and consumption of disposable plastic products are the most active and effective legislative responses. On December 31, 2007, China State Council issued the 'Notice on Restricting the Production and Sale of Plastic Shopping Bags', which was implemented from the 1st of June 2008, usually called special 'plastic limit order'. The main items of the 'plastic limit order' include a ban on the production, retail, and use of any plastic bag with a thickness of less than $0.025 \mathrm{~mm}$, and a system of payment for the provision of plastic bags in retail establishments. By the end of 2020, the 'plastic limit order' has been released and implemented for more

Jianli Liu

jian-li.liu@hotmail.com

1 School of Textile Science and Engineering, Jiangnan University, Wuxi 214021, China

2 Jiangsu Provincial Academy of Environmental Science, Nanjing 210036, China

3 State Key Laboratory of Environmental Criteria and Risk Assessment, Chinese Research Academy of Environmental Sciences, Beijing 100012, China

4 MOE Key Laboratory of Environment Remediation and Ecological Health, College of Environmental and Resource Sciences, Zhejiang University, Hangzhou 310058, China

5 School of Environmental and Civil Engineering, Jiangnan University, Wuxi 214122, China than 10 years. Survey data in 2016 showed that the use of plastic shopping bags in supermarkets and shopping malls has generally reduced by more than $2 / 3$, and the cumulative reduction of plastic shopping bags is about 1.4 million tons (Zhu and Zhao 2016). Through the implementation of 'plastic limit order', supermarkets and shopping malls do not provide plastic shopping bags for free. Furthermore, public awareness and support for environmental protection have been greatly improved in China.

Nowadays, China is the largest plastic producer in the world. In 2020,76,032.2kt plastic products are produced in China, $135,877.0 \mathrm{kt}$ plastic products are domestically consumed, and only $16,000.0 \mathrm{kt}$ are reused, thus the regeneration utilization ratio is only 17.6\% (Zhanfeng and Wanjun 2021). In other words, the mismanaged plastic waste accounts for a high share. In 2019, the amounts of plastic waste are about $63,000 \mathrm{kt}$, including more than 20,000kt disposable plastic products such as plastic bags, agricultural film, packaging materials, bottles and launch boxes, which are the main sources of plastic pollution in China (Qi et al. 2021). More seriously, disposable shopping bags are still free of charge in vegetable market, grocery, and restaurant (Wang and $\mathrm{Li}$ 2021). If each person uses 10 shopping bags every year, 14 billion shopping bags are consumed and nearly produce 54 million kilograms of plastic wastes if each plastic bag is $3 \mathrm{~g}$. At the same time, with the rapid growth of express delivery service since 2010 , the waste of express delivery packaging materials has surged from 0.2 million 
metric tons (Mt) in 2007 to $9.2 \pm 5 \%$ Mt in 2018 in China (Su et al. 2020). In 2018, China's express delivery industry consumed about 5.3 billion woven bags and 24.5 billion plastic bags, and the packaging tape used in China can wrap around the earth 1077 times a year (Su et al. 2020). Additionally, the plastic products used in household electric appliances, vehicles, architectures are gradually entering the elimination period, which will be another source of plastic pollutants. More than $50 \%$ plastic wastes are discarded or landfilled, causing serious ocean, soil and freshwater system pollution (Qi et al. 2021; Sun et al. 2022). Some estimation models indicated that China has been one of the main ocean microplastic sources, contributing the highest share of mismanaged plastic waste with around $28 \%$ of the global total (Lebreton et al. 2017; Jambeck et al. 2015). Although the reliability of these models need more research, how to prevent and control waste plastic should be an important component of the national strategy in China (Li et al. 2019).

However, China's plastic pollution seems to be more serious in recent years, which may be generally attributed to two main reasons. One is the cost of plastic shopping bags is still very small, no more than 5 cents per shopping bag, thus 'plastic limit order' has not played a role in price leverage. Another is the use of disposable plastic bags, swabs, and plastic tableware that has sharply increased with the rapid development of emerging industries such as e-commerce, express delivery, and food delivery in the past 10 years (Duan et al. 2019; Lu et al. 2019; Liu et al. 2020). Notably, the disposable plastic packages used by e-commerce, express delivery, and food delivery are not subjected to the 'plastic limit order', which can be considered a grey area of law and regulation. The 'plastic limit order' has been released for more than 10 years and gradually failed to achieve the expected results, which cannot keep up with the new situation of plastic garbage.

It is clear that the 'plastic limit order' did not curb the excessive use of plastic products, and it is gradually losing its original mandatory effect on the new types of plastic packages. Therefore, new laws and regulations to prevent plastic pollution need to be imperatively formulated. In 2020, China government rolled out a series of laws and regulations that are amended and issued in a bid to regulate and control plastic pollution. This legislative progress in China is unprecedented, which could result in profound impacts on environment protection and sustainable development.

On January 16, 2020, China's National Development and Reform Commission (NDRC) and the Ministry of Ecology and Environment (MEE) jointly released the "Opinions on Further Strengthening the Control of Plastic Pollution", to ban and significantly reduce the production and use of environmentally unfriendly plastic production in the next 5 years. A phased and feasible schedule to further strengthen the prevention and control of plastic pollution has been clarified in the Opinions. The disposable plastic tableware and swabs have been prohibited through cutting off the chain of production and sales in catering industry by the end of 2020. For daily chemicals containing plastic microbeads, production will be banned by 2020 , while sales will stop by the end of 2022 (Xinhuanet 2020). Non-degradable disposable straws have been banned in the whole catering industry in China by the end of 2020. The disposable plastic tableware will be prohibited in cities by the end of 2020, which will be extended to all counties on December 31st 2022. Further, the non-degradable disposable plastic tableware are widely used in take-out in cities, which will be gradually restricted and reduced by $30 \%$ by the end of 2025 . The disposable plastic wares used in hotel industry will also be banned by 2025 . The fast expansion of postal and express delivery industry has caused serious plastic pollution, especially the use of plastic packaging, plastic tape, and plastic woven bags, which will be banned by the end of 2025 . At the same time, ultra-thin plastic bags and agricultural films with a thickness less than $0.025 \mathrm{~mm}$ and $0.01 \mathrm{~mm}$ will also be prohibited. The medical waste and imported plastic waste will also be banned on recycle. In the future, the alternative and degradable materials are encouraged to prevention and control plastic pollution. A binding agreement to address the life cycle of plastic and eliminate plastic pollution will be established in China.

Degradable plastics are considered attractive alternatives for petroleum-based non-degradable plastics, especially single-use plastic bags (Abdelmoez et al. 2021). However, the definition of degradable plastic is still vague to the public on the terminology surrounding compostable plastics, bioplastics, bio-based plastics, and biodegradable and oxo-degradable plastics. The degradable plastics mainly refer to the plastics made of natural biodegradable and oxo-degradable materials, such as cellulose, starch, chitosan, and proteins from algae, plant, and animals, which degrades at the molecular or polymer level and convert to $\mathrm{CO}_{2}$ and biomass under biological action, or heat and light physicochemical action, or multifunctional actions (Chia et al. 2020). The utilization of biodegradable and oxo-degradable plastics, such as biopolymers produced from natural resources seem to be the future direction for single-use plastic bags in China.

On April 29, 2020, the "Law of the People's Republic of China on the Prevention and Control of Environmental Pollution by Solid Wastes" was revised and passed by China's highest legislature-the national people's congress and came into force on September 1, 2020. Referencing Article 69, China prohibits and restricts the production, sale, and use of non-degradable plastic bags and other disposable plastic products under the law. The use and recycling of plastic bags and other disposable plastic products in commercial and post fielding shall be reported under relevant national regulations. So far, plastic products have been formally 
adopted as an object in Chinese law, which will initiate rapid and widespread impacts on the prevention and control of plastic pollution. However, the lack of systematic measures and legislative framework for the prevention and control of plastic pollution in China has long been criticized by the international community and scholars to be outdated and formal (Fu et al. 2020). The revised law is exactly what China and the world long called for in environmental protection, which could help to steer China towards a more sustainable development path in the plastic industry.

On July 10, 2020, NDRC, MEE, together with eight other ministries jointly released the "Notice on making solid progress in the treatment of plastic pollution" to ensure the efforts to achieve the 2020 goal. The notice required that the detailed and feasible plan of each province should be issued before mid-August, 2020. A nationwide inspection on the plastic ban and restriction in key areas, such as shopping malls, supermarkets, grocery markets, and catering industries, has been carried out. By the end of 2020, a joint inspection on plastic pollution control has been carried out by MEE and NDRC. The detailed tasks of treatment of plastic pollution in 2020 are summarized in Table 1.

On August 28, 2020, China's Ministry of Commerce (MOC) published a Notice, titled "Further Strengthening Plastic Pollution Control in Business Fields". MOC also set forth the specifications and deadlines for banned and limited plastic products in the Notice, according to the National Plastics Pollution Control Plan with the three-phased goals of 2020, 2022, and 2025. Details of the specifications and deadlines are summarized in Table 2.

In the Notice, MOC also stipulated that local authorities shall facilitate the establishment of a centralized purchase and sale system for shopping bags in grocery markets. Concerning e-commerce businesses, food delivery, and other online business, local authorities are required to strengthen the supervision of these enterprises; draft alternative implementation plans for reducing the consumption of disposable plastic products; and promote alternative products that are reusable, recyclable, and degradable. However, there are some obstacles in the process of plastic alternatives. At present, degradable plastic bags are not completely universal in the commercial fields because of the higher cost. The disposable plastic bags used in supermarkets are generally 0.2 yuan for medium size and 0.3 yuan for large size, while degradable plastic bags are about 1 yuan each. At the same time, not all biodegradable replacements for petroleumbased products meet all sorts of standards. So far, attempts at viable replacements from renewable sources have faced limited success due to processing and economic constraints.

On November 27, 2020, MOC released an announcement, titled "the Measures for reporting the Use and Recycling of Disposable Plastic Products in the Commercial fielding (Trial)", which regulates all kinds of supermarkets, shopping malls, trade markets, and retail and catering enterprises providing take-out services through e-commerce platforms shall report the use and recycling of disposable plastic products. The disposable plastic products referred to in the measures include non-degradable plastic shopping bags, coiled bags, plastic packaging bags (including woven bags), nondegradable disposable plastic lunch boxes, plastic tableware (knives, forks, spoons), and plastic straws. MOC has established a national unified reporting system for the use and recycling of disposable plastic products to receive and process report information promptly to meet the requirements of the "Law of the People's Republic of China on the Prevention and Control of Environmental Pollution by Solid Wastes".

On December 14, 2020, eight departments of China, including the NDRC and the State Post Bureau, published new guidelines setting unified standards for green packaging to ensure compliance by industry players. To reduce the use of packaging materials and prevent pollution, China will push forward key measures to gradually halt the use of non-degradable plastic bags, woven bags, and adhesive tape (CGTN 2020). Secondary packaging and excessive packaging of packages are the potential main sources of plastic pollution, which will be gradually controlled in the future under the guidelines.

Fortunately, there is a basic law that establishes a legislative framework for plastic pollution now. Under Article 69 of the amended "Law of the People's Republic of China on the Prevention and Control of Environmental Pollution by Solid Wastes", the production, sale, and use of non-degradable plastic bags and other disposable plastic products have been prohibited and restricted since September 1, 2020. The use and recycling of plastic bags and other disposable plastic products in commercial and post fielding shall be reported under relevant national regulations. Additionally, some articles of law and legislations prohibit the open burning of plastic and restrict the use of non-degradable plastic products in "Air Pollution Prevention and Control Law of the People's Republic of China" and "Yangtze River Protection Law of the People's Republic of China", respectively. Fortunately, some regulations and regulatory documents of provincial and municipal governments, such as Garbage Classification Action (Tong et al. 2020) and Regulation for Civilized Behavior promotion (Xinhuanet 2021), are effective supplements.

China is the world's biggest plastic producer and consumer in the past 10 years. In 2008, China banned free plastic bags, effectively reducing their use in retailing. However, the rapid expansion of e-commerce, express, and food delivery industries has brought about new challenges. Notably, the disposable plastic packages used by e-commerce, express delivery, and food delivery are not subjected to the "plastic limit order' released in 2008 , which can be considered a grey 


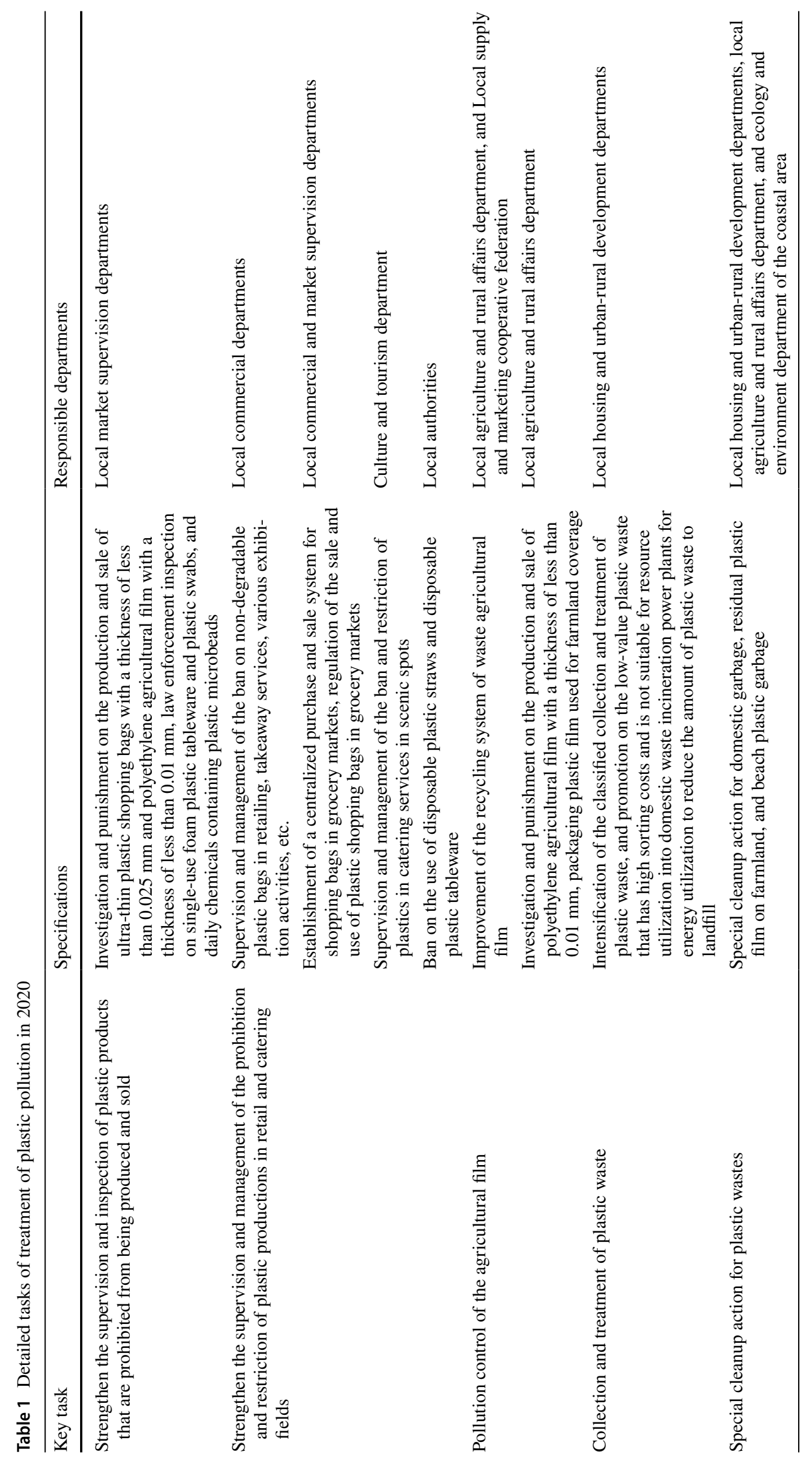


Table 2 Phased tasks of banned and limited plastic products in the business field

\begin{tabular}{|c|c|c|c|}
\hline Banned and limited plastic products & Specifications & Applicable regions & Deadline \\
\hline \multirow[t]{3}{*}{ Non-degradable plastic bags } & $\begin{array}{l}\text { Ban on the use of non-degradable plastic } \\
\text { bags in shopping malls, supermarkets, } \\
\text { catering delivery services, and various } \\
\text { exhibition activities }\end{array}$ & $\begin{array}{l}\text { Municipalities, provincial capitals, and } \\
\text { urbanized area in the cities specifically des- } \\
\text { ignated in the national development plan }\end{array}$ & End of 2020 \\
\hline & $\begin{array}{l}\text { Standardization and restriction on the use } \\
\text { of non-degradable plastic bags in grocery } \\
\text { markets }\end{array}$ & $\begin{array}{l}\text { All urbanized area of the cities at prefecture } \\
\text { level and all built-up county area in the } \\
\text { coastal regions }\end{array}$ & End of 2022 \\
\hline & $\begin{array}{l}\text { Ban on the use of non-degradable plastic } \\
\text { bags in grocery markets }\end{array}$ & $\begin{array}{l}\text { All urbanized area of the cities at prefecture } \\
\text { level and all built-up county area in the } \\
\text { coastal regions }\end{array}$ & End of 2025 \\
\hline \multirow[t]{4}{*}{ Disposable plastic tableware } & $\begin{array}{l}\text { The catering industry prohibits the use of } \\
\text { non-degradable disposable plastic straws }\end{array}$ & Nationwide & End of 2020 \\
\hline & $\begin{array}{l}\text { Ban on the use of non-degradable dispos- } \\
\text { able plastic tableware in dine-in catering } \\
\text { services }\end{array}$ & $\begin{array}{l}\text { Urbanized area of the cities at and above } \\
\text { prefecture level }\end{array}$ & End of 2020 \\
\hline & $\begin{array}{l}\text { Ban on the use of non-degradable dispos- } \\
\text { able plastic tableware in dine-in catering } \\
\text { services }\end{array}$ & Built-up county area & End of 2025 \\
\hline & $\begin{array}{l}\text { Consumption of non-degradable disposable } \\
\text { plastic tableware in the catering delivery } \\
\text { business decreased by } 30 \%\end{array}$ & Cities at and above prefecture level & End of 2025 \\
\hline \multirow[t]{2}{*}{$\begin{array}{l}\text { Disposable plastic products in the } \\
\text { hospitality industry }\end{array}$} & $\begin{array}{l}\text { No longer offering disposable plastic prod- } \\
\text { ucts in star hotels, guesthouses, etc. }\end{array}$ & Nationwide & End of 2022 \\
\hline & $\begin{array}{l}\text { The above implementation extended to all the } \\
\text { hotels, guesthouses, and homestay }\end{array}$ & & End of 2025 \\
\hline
\end{tabular}

area of law and regulation. So, compared with the abolished ones, the series of laws and regulations were unprecedented in 2020 have the following characteristics.

(1) Higher administrative and legal effectiveness. A series of laws, regulations, bans, rules and notes have been jointly released by China's highest legislature-the national people's congress, China's highest planning body, the National Development and Reform Commission (NDRC), and other closely related states administrative functional departments, such as the Ministry of Ecology and Environment, the State Administration for Market Regulation. From the perspective of legislation, China has promised rules on plastic products and an accelerated switch to less plastic pollution.

(2) More single-use and non-degradable plastic products are included. In China's 2008 restriction on ultra-thin plastic bags, only the bags thinner than $0.025 \mathrm{~mm}$ are banned. The new plan imposes comprehensive restrictions on other single-use, non-degradable plastic products, except for single-use plastic bags. The new measures detailed and carried out in the phased plan focus on the highly visible waste packaging generated by the rise of online retail and the popularity of takeaway food, which have been fast-growing industries in China since 2010. Now, single-use plastic straws are vanishing in China as the first phase of the country's most stringent plastic ban takes effect in dine-in catering services.

(3) More challenging but feasible plan. The phased plan with step-by-step timelines to ban and significantly reduce plastic use in the next 5 years is not only ambitious but feasible for China as the world's biggest plastic producer and consumer. In 2019, China produced more than 80 million tons of plastic products, while the lack of recycling and reuse has been a persistent social and environmental challenge. Given that China is already working to tackle plastic pollution, there is also a great challenge to address this persistent social and environmental problem in a short period. However, the new plan to ban single-use and non-degradable plastics, such as shopping bags and straws in online retail and takeaway food industries has promised rules on plastic products that are comprehensive and detailed, as well as more bans, and an accelerated switch to fewer polluting materials in China.

As of January 1, 2021, 31 provinces in China mainland have issued relevant implementation plans or action plans for plastic pollution control. Taking Hainan Province as an example, the Joint Law Enforcement Action Plan for the Prohibition of Plastics in Hainan Province in 2021 focuses 
on six key industries, including catering, takeaway platform, wholesale and retail, e-commerce express delivery, accommodation and exhibition, and agricultural production, to strengthen plastic reduction. In the action, an eight-month pilot work to promote the implementation of the plastic ban by signing a commitment to ban plastic has been carried out in government institutions, state-owned enterprises, schools, tourist attractions, large supermarkets, hospitals and other key industries. During the pilot period, large supermarkets removed the prohibited disposable non-degradable plastic products and began to sell substitutes such as paper products and bio-based products. The orders of substitute manufacturers in Hainan Province greatly increased, with sales of more than 4500 tons of substitutes. Up to May 25th, 2021, a total of 13,968 law enforcement officers have been dispatched to inspect 26,858 business entities, 1724 cases have been filed, 947 cases have been closed, a fine of 2.4421 million yuan has been imposed, and more than 10 million disposable non-degradable plastic products have been seized. As of June 2021, China has made some achievements in the organization and leadership, system establishment, alternative industry planning, market supervision and publicity and guidance of plastic pollution prevention and control.

The Chinese government will improve its legislative oversight for regulating plastic production, sales, consumption, and waste management through the unprecedented political will and public desire toward plastic pollution. The legislative efforts to control and prevent plastic pollution are only among the first steps. We can do much more to solve plastic pollution. We provide some suggestions as to the following from different perspectives.

Firstly, China should set up a national environmental education foundation to cultivate an environmentally conscious and responsible public. Environmental education will further enhance the control of plastic pollutants and facilitate effective law enforcement through increasing public awareness and knowledge, and providing the public with the necessary skills to take responsible action. The public, especially students, in China are learning about environmental problems and creatively developing solutions for plastic pollution. The knowledge, policy, and law education about plastic production, microplastic pollution, and plastic recycling in schools and communities can achieve the highest reduction in mismanaged plastic waste with the lowest effort and promote a revolutionary movement to rethink plastic (Cordier et al. 2021).

Secondly, China should reform and improve the pollution prevention and control system to prevent plastic pollution at the source. Strengthen the primary-level management capacity of sale, consumption, and recycling of plastic products for small businesses, such as nonchain retail stores, rural bazaars, and grocery markets. An easy-access system to facilitate a complaint about plastic pollution for the public should be set up. The application of new digital technologies includes big data, artificial intelligence, machine learning, and cloud computing in areas, such as pollution source monitoring, tracing, microplastic transfer pathways, and detection of types of pollutants.

Thirdly, China should implement positive trade-related policies concerning plastics. Being the biggest plastic producer and consumer in the world, China's trade plays a central role not only in the global plastics economy but also in plastic pollution. In 2017, China's plastic import ban has played an enormous impact on Chinese environmental sustainability, which also will increase the prospects of environmental impact mitigation of plastic waste trade flow worldwide (Wen et al. 2021). To prevent and control plastic pollution in the long run, China should gradually amid impressive and multiplying efforts including import and export policy of raw materials and plastic products, and plastic waste trade regulations across the globe to address plastic pollution.

Fourthly, some emerging plastic pollutants should be adopted as a formal legislative object in the law framework of China through amending and constituting the related regulations. As yet, the new types of plastic pollutants, microplastic and microfibers, and the emerging sources of plastic pollution, plastic personal protective equipment related to the COVID-19 pandemic, have not been adopted as a formal legislative object in China laws (Xu et al. 2020; Ammendolia et al. 2021; Liu et al. 2021). However, microplastic pollution has contaminated the whole planet, from Arctic snow and mountain soils to many rivers, lakes, and the deepest oceans (Katija et al. 2017; Miller et al. 2017; Bergmann et al. 2019; Seeley et al. 2020). Some researches indicated that microplastic pollution is more dangerous in the long term than plastic pollution because of its small size, durability, environmental toxicology, and potential human health risk (Sharma and Chatterjee 2017; Alimba and Faggio 2019; Everaert et al. 2020). China could learn more from international conventions to develop regulations and laws related explicitly to microplastics pollution (Xu et al. 2020).

Fifthly, the circular plastics economy provides emerging opportunities for controlling plastic pollution in China. Nowadays, China is the largest plastic producer in the world, accounting for nearly one-third of the global plastics production ( $\mathrm{Li}$ et al. 2019). The plastics industry has been an important pillar industry of China in the last 40 years. The plastic industry has brought wealth to China but also caused extremely serious environmental pollution. How to control plastic pollution through economic model innovation is another effective pathway for China government. Now, the Chinese government is speeding up efforts to decrease the proportion of the plastic industry, especially the disposable plastic production and sale, in the country's economy. In the next 5 years, a circular economy incorporated with energy 
conservation and environmental protection will be one of the important new pillar industries in China. The physical and chemical recycling of plastic for a circular plastics economy will provide emerging opportunities (Payne and Jones 2021). The circular plastics economy will promote the foundation researches and their applications about physical and chemical recycling and upcycling processes, including the conversion of plastics into their virgin monomers, liquid fuels, or chemical feedstocks to produce value-added products, which have been identified as the most promising strategy for recovering value from waste plastics (Chen et al. 2021).

China's legislations on plastic pollution prevention in 2020 are the right actions that are really needed to solve the environmental problem. Through the national plastics pollution control plan in the next 5 years, the consumption of disposable plastic products will be significantly reduced, and alternative products will be promoted in China. The Chinese laws and regulations may not be a perfect model, but China has established its own feasible and culturally nuanced solutions. To eliminate plastic pollution, a holistic approach is needed in China. China will continuously strengthen the existing legislations to strictly continue the momentum of green law. As the world's biggest plastic producer and consumer, China has the potential to be a global leader in effective control of domestic and international plastic pollution by strengthening its impressive and multiplying efforts across the globe to address plastic pollution.

Funding This project is supported by the National Natural Science Foundation of China (No. 51809118) and the Natural Science Foundation of Jiangsu Province, China (No. BK20170188).

\section{Declarations}

Conflict of interest The authors declare that they have no conflict of interest.

\section{References}

Abdelmoez W, Dahab I, Ragab EM et al (2021) Bio- and oxo-degradable plastics: insights on facts and challenges. Polym Adv Technol 32:1981-1996. https://doi.org/10.1002/pat.5253

Alimba CG, Faggio C (2019) Microplastics in the marine environment: current trends in environmental pollution and mechanisms of toxicological profile. Environ Toxicol Pharmacol 68:61-74. https://doi.org/10.1016/j.etap.2019.03.001

Ammendolia J, Saturno J, Brooks AL et al (2021) An emerging source of plastic pollution: environmental presence of plastic personal protective equipment (PPE) debris related to COVID-19 in a metropolitan city. Environ Pollut 269:116160. https://doi.org/10. 1016/j.envpol.2020.116160

Bergmann M, Mützel S, Primpke S et al (2019) White and wonderful? Microplastics prevail in snow from the Alps to the Arctic. Sci Adv 5:eaax1157. https://doi.org/10.1126/sciadv.aax1157
CGTN (2020) "Green drive" to make China's express delivery sector more eco-friendly. In: www.cgtn.com. https://news.cgtn. com/news/2020-12-27/-Green-drive-to-make-express-deliverysector-more-eco-friendly-Wz9gXfsFG0/index.html. Accessed 27 Dec 2020

Chen H, Wan K, Zhang Y, Wang Y (2021) Waste to wealth: chemical recycling and chemical upcycling of waste plastics for a great future. ChemSusChem. https://doi.org/10.1002/cssc.202100652

Chia WY, Ying Tang DY, Khoo KS et al (2020) Nature's fight against plastic pollution: algae for plastic biodegradation and bioplastics production. Environ Sci Ecotechnol 4:100065. https://doi. org/10.1016/j.ese.2020.100065

Cordier M, Uehara T, Baztan J et al (2021) Plastic pollution and economic growth: the influence of corruption and lack of education. Ecol Econ 182:106930. https://doi.org/10.1016/j.ecole con.2020.106930

Duan H, Song G, Qu S et al (2019) Post-consumer packaging waste from express delivery in China. Resour Conserv Recycl 144:137-143. https://doi.org/10.1016/j.resconrec.2019.01.037

Everaert G, De Rijcke M, Lonneville B et al (2020) Risks of floating microplastic in the global ocean. Environ Pollut 267:1-9. https://doi.org/10.1016/j.envpol.2020.115499

Fu D, Chen CM, Qi H et al (2020) Occurrences and distribution of microplastic pollution and the control measures in China. Mar Pollut Bull 153:110963. https://doi.org/10.1016/j.marpo lbul.2020.110963

Jambeck JR, Geyer R, Wilcox C et al (2015) Plastic waste inputs from land into the ocean. Science 80-:769-771

Katija K, Choy CA, Sherlock RE et al (2017) From the surface to the seafloor: how giant larvaceans transport microplastics into the deep sea. Sci Adv 3:e1700715. https://doi.org/10.1126/sciadv. 1700715

Lebreton LCM, Van Der Zwet J, Damsteeg JW et al (2017) River plastic emissions to the world's oceans. Nat Commun 8:1-10. https://doi.org/10.1038/ncomms 15611

Li D, Peng G, Zhu L (2019) Progress and prospects of marine microplastic research in China. Anthr Coasts 2:330-339. https://doi. org/10.1139/anc-2018-0014

Liu G, Agostinho F, Duan H et al (2020) Environmental impacts characterization of packaging waste generated by urban food delivery services: a big-data analysis in Jing-Jin-Ji region (China). Waste Manag 117:157-169. https://doi.org/10.1016/j. wasman.2020.07.028

Liu J, Vethaak AD, An L et al (2021) An environmental dilemma for China during the COVID-19 pandemic: the explosion of disposable plastic wastes. Bull Environ Contam Toxicol. https://doi. org/10.1007/s00128-021-03121-x

Lu X, Vogt RD, Li H et al (2019) China's ineffective plastic solution to haze. Science 364:1145-1145. https://doi.org/10.1126/ science.aax 5674

Miller RZ, Watts AJR, Winslow BO et al (2017) Mountains to the sea: river study of plastic and non-plastic microfiber pollution in the northeast USA. Mar Pollut Bull 124:245-251. https://doi. org/10.1016/j.marpolbul.2017.07.028

Payne J, Jones MD (2021) The chemical recycling of polyesters for a circular plastics economy: challenges and emerging opportunities. ChemSusChem. https://doi.org/10.1002/cssc.202100400

Qi W, Jinping Q, Bi S et al (2021) Prevention and control of waste plastics pollution in China. Chin J Eng Sci 23:160-166. https:// doi.org/10.15302/J-SSCAE-2021.01.020

Seeley ME, Song B, Passie R, Hale RC (2020) Microplastics affect sedimentary microbial communities and nitrogen cycling. Nat Commun 11:1-10. https://doi.org/10.1038/s41467-020-16235-3 
Sharma S, Chatterjee S (2017) Microplastic pollution, a threat to marine ecosystem and human health: a short review. Environ Sci Pollut Res 24:21530-21547. https://doi.org/10.1007/ s11356-017-9910-8

Su Y, Duan H, Wang Z et al (2020) Characterizing the environmental impact of packaging materials for express delivery via life cycle assessment. J Clean Prod 274:122961. https://doi.org/10.1016/j. jclepro.2020.122961

Sun Q, Li J, Wang C et al (2022) Research progress on distribution, sources, identification, toxicity, and biodegradation of microplastics in the ocean, freshwater, and soil environment. Front Environ Sci Eng 16:1-14. https://doi.org/10.1007/s11783-021-1429-Z

Tong Y, Liu J, Liu S (2020) China is implementing "Garbage Classification" action. Environ Pollut 259:2019-2020. https://doi.org/ 10.1016/j.envpol.2019.113707

Wang B, Li Y (2021) Plastic bag usage and the policies: a case study of China. Waste Manag 126:163-169. https://doi.org/10.1016/j. wasman.2021.03.010

Wen Z, Xie Y, Chen M, Dinga CD (2021) China's plastic import ban increases prospects of environmental impact mitigation of plastic waste trade flow worldwide. Nat Commun 12:1-9. https://doi.org/ $10.1038 / \mathrm{s} 41467-020-20741-9$
Xinhuanet (2020) China reveals plan to cut plastic use by 2025. In: Xinhuanet. http://www.china.org.cn/china/2020-01/19/content_ 75629958.htm. Accessed 28 Jan 2021

Xinhuanet (2021) China focus: Beijing releases regulation for civilized behavior promotion. In: XINHUANET

$\mathrm{Xu} \mathrm{Y}$, Chan FKS, He J et al (2020) A critical review of microplastic pollution in urban freshwater environments and legislative progress in China: recommendations and insights. Crit Rev Environ Sci Technol. https://doi.org/10.1080/10643389.2020.1801308

Zhanfeng M, Wanjun J (2021) China plastic industry 2020. China Plast $35: 119-125$

Zhu J, Zhao Z (2016) 'Plastic Limit Order' has been implemented since 2008 and accumulatively reduced plastic bags by 1.4 million tons. In: Renmin Ribao. http://www.xinhuanet.com/politics/2016-02/ 17/c 128725138.htm. Accessed 17 Feb 2016

Publisher's Note Springer Nature remains neutral with regard to jurisdictional claims in published maps and institutional affiliations. 